\title{
Development and evaluation of novel tumor-targeting paclitaxel-loaded nano- carriers for ovarian cancer treatment: in vitro and in vivo
}

\author{
Shu Yao ${ }^{1,2+}$, Li Li $\mathrm{Li}^{1,2+}$, Xuan-tao Su${ }^{3}$, Kai Wang ${ }^{4}$, Zai-jun Lư ${ }^{4}$, Cun-zhong Yuan ${ }^{1,2}$, Jin-bo Feng ${ }^{1,2}$, Shi Yan ${ }^{1,2}$,
} Bei-hua Kong ${ }^{1,2}$ and Kun Song ${ }^{1,2^{*}}$

\begin{abstract}
Background: Ovarian cancer is the most leading cause of death and the third most common gynecologic malignancy in women. Traditional chemotherapy has inevitable drawbacks of nonspecific tumor targeting, high toxicity, and poor therapeutic efficiency. In order to overcome such shortcomings, we prepared a novel nano-carrier drug-delivery system to enhance the anti-tumor efficiency.

Methods: In vitro characterizations of nano-carriers were determined by TEM, DLS. Cell viability was measured by MTT method. RT-PCR was performed to measure the expression of FARa in three ovarian cancer cell lines. The drug-release study and the uptaken study were measured in vitro. The pharmacokinetic and the drug distribution study were verified by HPLC methods in vivo. The enhanced anti-tumor efficiency of FA-NP was evaluated by the tumor inhibitory rate in vivo.

Results: Paclitaxel (PTX)-loaded nanoparticles (NPS) (PTX-PEG-PLA-NP and PTX-PEG-PLA-FA-NP) were prepared successfully, and the drug-release study showed that the cumulative release rates of NP groups were much less than free PTX group. The pharmacokinetic study showed that the elimination phase of two kinds of NP groups were much longer than that of PTX group. The drug distribution in different tissues showed that the peak-reach time was $2 \mathrm{~h}$ in the PTX group and $6 \mathrm{~h}$ in both NP groups. All of these results confirmed the excellent slow-release effects of both kinds of nano-carriers. More importantly, we confirmed that PTX-PEG-PLA-FA-NP had greater uptake by SK-OV-3 cells than PTX-PEG-PLA-NP and free PTX in vitro. A drug-distribution study of tumor-bearing mice demonstrated that the PTX concentration of tumor tissues in the PTX-PEG-PLA-FA-NP group was 3 times higher than the other two groups. PTX-PEG-PLA-FA-NP was uptaken much more by SK-OV-3 cells than PTX-PEG-PLA-NP and free PTX. Eventually, based on the slow-release effect and tumor-targeting characteristics of PTX-PEG-PLA-FANP, a cytotoxicity test indicated that PTX-PEG-PLA-FA-NP was much more toxic to SK-OV-3 cells than the controls. The tumor inhibitory rate in the PTX-PEG-PLA-FA-NP group of tumor-bearing mice was about 1.5 times higher than the controls. The tumor targeting and anti-tumor efficiency of PTX-PEG-PLA-FA-NP were confirmed both in vitro and in vivo.

(Continued on next page)
\end{abstract}

\footnotetext{
*Correspondence: songkun2001226@sdu.edu.cn

${ }^{\dagger}$ Equal contributors

'Department of Obstetrics and Gynecology, Qilu Hospital, Shandong

University, 107 Wenhua Xi Road, Jinan, Shandong 250012, People's Republic

of China

${ }^{2}$ Gynecology Oncology Key Laboratory, Qilu Hospital, Shandong University,

Jinan, Shandong 250012, China

Full list of author information is available at the end of the article
} 
(Continued from previous page)

Conclusions: We developed an ovarian cancer targeting nano-carrier drug delivery system successfully, which showed perfect ovarian cancer targeting and anti-tumor effect, thus have the potential to be a new therapy strategy for ovarian cancer patients.

Keywords: Nano-carriers, Ovarian cancer, Paclitaxel, Tumor targeting, Folic acid

\section{Background}

Ovarian cancer is a leading cause of death and the third most common gynecologic malignancy in women $[1,2]$. The 5-year survival rate of advanced stage ovarian cancer patients is presently only approximately $30 \%$ [3]. Paclitaxel combined with platinum drugs are the first-line chemotherapy choices for ovarian cancer patients [4]. However, traditional PTX chemotherapy has serious side effects because of the lack of selectively to tumor tissues. To overcome this defect, several strategies such as gene therapy, immunotherapy, and molecular-targeted therapy were developed but have thus shown limited effects in ovarian cancer [5].

In recent years, nanotechnology has shown promising prospects in medicine and made breakthrough progress in the cancer diagnosis and treatment field [6, 7]. Nanocarriers have been widely developed and have shown promising tumor-targeting characteristics [8]. For example, liposomal doxorubicin has achieved good treatment effects in ovarian cancer patients $[9,10]$. However, all nano-agents in clinical applications such as liposomal doxorubicin have limited tumor-targeting effects because no active tumortargeting mechanism exists. Folic acid (FA) plays an important role in cell metabolism and DNA synthesis and repair [11]. Folic acid receptors (FAR) usually over-express in ovarian cancer cells $[12,13]$. Therefore, the FA molecule can serve as a specific targeting substance to combine with FAR, which might help us realize the active targeting effect in tumor tissues $[14,15]$.

In this study, PTX-loaded polyethylene glycol poly (lactic acid) (PEG-PLA) nano-carriers with or without FA molecules (PTX-PEG-PLA-NP and PTX-PEG-PLAFA-NP) were prepared successfully. The slow-release effects of the nano-carriers were analyzed by drug release experiment in vitro and pharmacokinetic traits as well as tissue-distribution studies in vivo. The uptake experiment in vitro and the tissue-distribution experiment in tumorbearing animals were performed to demonstrate the tumor-targeting characteristics of PTX-PEG-PLA-FA-NP. Eventually, the anti-tumor efficiency of those two kinds of nano-delivery systems was tested both in vitro and in vivo.

\section{Methods}

\section{Materials}

Loctite, PLA, ethanol, diethyl ether, methanol, tetrahydrofuran (THF), dichloromethane (DCM), polyvinyl alcohol, acetonitrile, epoxy ethane, PTX (99\% purity), MTT (3-[4,5-dimethylthiazol-2-yl]-2,5-diphenyltetrazolium bromide), hexamethyl-disiliconate potassium (KHMDS), dimethyl sulfoxide, SYBR Green Master Mix, and FA were purchased from Fule Biological Technology Co., Ltd. (Jinan, China). TRIzol reagent was supplied by Pufei (Shanghai, China). Moloney murine leukemia virus (M$\mathrm{mlV}$ ), dNTPs, and RNase inhibitor were obtained from Promega Corp. (Madison, WI, USA).

\section{Preparation of PEG-PLA-NP and PEG-PLA-FA-NP}

In an argon (Ar) gas environment, $10 \mathrm{~g}$ of recrystallized lactide was added to conjoined bottle A. THF $(20 \mathrm{ml})$, KHMDS $(1.5 \mathrm{ml})$, and epoxy ethane $(2.4 \mathrm{ml})$ were added to conjoined bottle $\mathrm{B}$, which then was stirred for 2 days. Subsequently, the solution in bottle B was poured into bottle A and stirred for $2 \mathrm{~h}$ at $25{ }^{\circ} \mathrm{C}$. Finally, $20 \mathrm{ml}$ of anhydrous acetic acid was added to bottle A and stirred again for $30 \mathrm{~min}$. HCL $(0.2 \mathrm{ml})$ was added to stop the action to form a PEG-PLA block co-polymer. FA was then added for another $24 \mathrm{~h}$ of stirring to form PEGPLA-FA-NP.

\section{Preparation of PTX-PEG-PLA-NP and PTX-PEG-PLA-FA-NP} PEG-PLA-NP or PEG-PLA-FA-NP (300 mg) dissolved in THF $(1 \mathrm{ml})$ was mixed with PTX $(50 \mathrm{mg})$ dissolved in methylene chloride $(1 \mathrm{ml})$. Subsequently, $3 \mathrm{ml}$ of polyvinyl alcohol was added. The mixed solution was then added to ultrapure water at a speed of 0.4 to $0.6 \mathrm{ml} / \mathrm{min}$ and ultra-sonicated at $300 \mathrm{~W}$ for $20 \mathrm{~min}$. The emulsion was stirred for $4 \mathrm{~h}$ to obtain the precipitate. The PTXloaded nano-carriers were then ready.

\section{Characterization of PTX-loaded nano-carriers}

The particle size and zeta potential (ZP) of PTX-PEGPLA-NP and PTX-PEG-PLA-FA-NP were analyzed using 90-Plus Zeta PALS instrument (Malvern Instruments Ltd., Malvern, UK). Transmission electron microscopy (TEM; Tecnai G2F20 S-Twin, FEI Company, Hillsboro, OR, USA) was used to determine the morphology and surface characteristics of the nano-carriers. Nuclear magnetic resonance spectroscopy (HNMR) was used to test the chemical formula of PEG-PLA-NP and PEG-PLA-FA-NP. The amount of PTX encapsulated in the nano-carriers was measured using high-performance liquid chromatography (HPLC, Agilent Technologies, Palo Alto, CA, USA). 
The drug encapsulation efficacy (EE) and drug loading (DL) were obtained through the following equations:

$$
\begin{aligned}
& \mathrm{EE}(\%)=\text { mass of drug incorporated }(\mathrm{mg}) \\
& \quad / \text { initial drug added to the medium }(\mathrm{mg}) \times 100 \% \\
& \mathrm{EE}(\%)=\text { mass of drug incorporated }(\mathrm{mg})
\end{aligned}
$$$$
\text { / initial drug added to the medium }(\mathrm{mg}) \times 100 \%
$$

\section{Release study of nano-carriers in vitro}

The release profiles of PTX from nano-carriers were investigated using the dialysis method. First, PTX-PEGPLA-NP, PTX-PEG-PLA-FA-NP, and free PTX were dissolved in THF $(1 \mathrm{ml})$ and then placed in a dialysis bag (SnakeSkin, Pierce Biotechnology, Rockford, IL, USA) (3500 KDa) and then immersed in $50 \mathrm{ml}$ of phosphate-buffered saline (PBS). At each predetermined time point $(1,2,4,6,12,24,48,72,96,125$, and $160 \mathrm{~h})$, $5 \mathrm{ml}$ of PBS was removed and another $5 \mathrm{ml}$ of fresh PBS was added. The PTX concentration in the removed PBS was then analyzed using HPLC to determine the released PTX content.

\section{FARa expression in three ovarian cancer cell lines}

Human ovarian carcinoma cell lines SK-OV-3, HO8910, and A2780 were supplied by the Gynecology Oncology Key Laboratory of Qilu Hospital. The expression levels of folic acid receptor $\alpha($ FAR $\alpha)$ in 3 ovarian cancer cell lines were determined using realtime polymerase chain reaction (RT-PCR) testing. A2780, SKOV3 and HO8910 cells (STR for A2780, SKOV-3 and HO-8910 cells were shown in Additional file 1: Figures S1-S3.) were cultured in RPMI 1640 medium with $10 \%(v / v)$ fetal bovine serum (FBS) and 1\% (v/v) penicillin/streptomycin combination. Total RNA was isolated from the above cells using Trizol reagent respectively. Qualitative reverse transcription PCR was performed using Fast-Start Universal SYBR Green Master Mix. Primers for FR gene expression detection were $5^{\prime}-$ GAACGCCAAGCACCACAAG-3' (forward) and 5'GGTCGACACTGCTCATGCAA-3' (reverse). Data analysis was performed using the comparative $\mathrm{Ct}$ method $(2 \Delta \Delta \mathrm{Ct})$.

\section{Cellular uptake study of nano-carriers}

Cellular uptake characteristics of two kinds of nanocarriers were analyzed by fluorescence microscopy (Olympus, Tokyo, Japan). Fluorescent marker FITC was combined with PEG-PLA-NP or PEG-PLA-FA-NP. Two kinds of FITC-NP solutions were co-incubated with 3 different ovarian cancer cells for different intervals $(1,2$, 4,6 , and $12 \mathrm{~h}$ ). We normalized the FITC fluorescence to
DAPI to test the different cellular densities of different cell types to in the cell uptake experiment. PEG-PLAFA-NP samples with different FA percentages (5\%, 10\%, and $20 \%)$ were also prepared and co-incubated with SKOV-3 cells to verify the influence of the FA concentration on cellular uptake. In order to verity FAR-mediated tumor targeting, competition assay using different concentration FA contained culture medium $(0 \mu \mathrm{g} / \mathrm{ml}$, $5 \mu \mathrm{g} / \mathrm{ml}, 20 \mu \mathrm{g} / \mathrm{ml}$ and $50 \mu \mathrm{g} / \mathrm{ml}$ in cell culture medium) were performed to test whether PTX-PEGPLA-FA-NP uptake is FAR-specific on SK-OV-3 cells or not. The intracellular fluorescence images were observed, and the fluorescence intensity was analyzed using Image J software (National Institutes of Health, Rockville, MD, USA).

\section{Cytotoxicity assay in vitro}

The cytotoxicity of the blank NP solution and two kinds of PTX-NPs were assessed by the MTT assay. Different concentrations of the PEG-PLA-NP solutions $(0-100 \mu \mathrm{g} / \mathrm{ml})$ were used to test the cytotoxicity of the blank nanocarriers. Furthermore, standard solutions (PTX, PTX-PEGPLA-NP, and PTX-PEG-PLA-FA-NP with 10, 25, 50, 75, and $100 \mu \mathrm{g} / \mathrm{ml}$ in PTX concentration) were co-incubated with SK-OV-3 cells at different intervals (12, 24, 36, and $48 \mathrm{~h})$. The MTT test was then performed as described before [16].

\section{Pharmacokinetic data analysis in rats}

Female Sprague-Dawley rats ( $n=6 /$ group $)$ received intravenous injections of PTX or PTX nano-carriers (6 $\mathrm{mg} / \mathrm{kg}$ in PTX concentration). Blood samples were collected at predetermined time points $(10,20,30$, and 40 min and 1, 2, 4, 6, 8, 12, 24, 48, and $60 \mathrm{~h}$ ). We mixed methanol $(200 \mu \mathrm{l})$ and diethyl ether $(2 \mathrm{ml})$ with plasma $(200 \mu \mathrm{l})$ samples, vortexed for $5 \mathrm{~min}$ and centrifuged at 10,000 rpm for $10 \mathrm{~min}$, then dried the samples under nitrogen conditions. The PTX concentrations were then analyzed using HPLC technology for each sample.

\section{Tissue-distribution study in tumor-bearing mice}

The experimental protocol of the animals in this research was approved by the Animal Ethics Committee of Shandong University (DWLL-2015-001). Healthy female athymic mice (BALB/c nu-nu) (4-6 weeks old) were supplied by the Experimental Animal Center of Shandong University in Jinan, China. SK-OV-3 ovarian cancer cells $\left(1.0 \times 10^{7}\right)$ were implanted subcutaneously or intraperitoneally into the mice to establish subcutaneous or abdominal tumor-bearing models. To establish the standard curve of PTX, blood and tissue samples (liver, spleen, kidney, heart, lung, uterus, small intestine, and tumor tissues) from tumor-bearing mice were homogenized with $5 \mathrm{ml}$ of PBS. Subsequently, $20 \mu \mathrm{l}$ different quantitative standard 
PTX solutions $(0.95,1.9,9.5,19,38,76$, and $152 \mu \mathrm{g} / \mathrm{ml})$ were added to homogenate samples $(200 \mu \mathrm{l})$, followed by an HPLC test. The linear regression equation was then established based on the PTX concentration (X) and AUC (Y) value from the HPLC test. Abdominal tumor-bearing mice were randomly divided into 3 groups $(30$ mice/ group). Each mouse was intravenously injected with either PTX or PTX nano-carriers solution $(6 \mathrm{mg} / \mathrm{kg})$. At predetermined time points $(1,2,4,6,12$, and $24 \mathrm{~h}), 5$ mice in each group were euthanized; their plasma and tissue samples were quickly collected for an HPLC test and then calculated based on the linear regression equation mentioned above to determine the PTX concentration in the samples.

\section{Anti-tumor effect study in vivo}

The subcutaneous tumor-bearing animal mice were randomly divided into 4 groups (7/group). A single dose of PTX $(6 \mathrm{mg} / \mathrm{kg})$ in free PTX, PTX-PEG-PLA-NP, or PTXPEG-PLA-FA-NP groups was intravenously administered to each mouse and saline solution was used as a control. Each injection was repeated every 3 days for a total of 6 consecutive injections [17]. The tumor sizes and animal body weights were then measured every 3 days. Tumor size was calculated using the formula $V=\left(a b^{2}\right) / 2$, where $a$ represents the longest diameter and $b$ represents the diameter orthogonal to $a(\mathrm{~mm})$.

\section{Statistical analysis}

Statistical evaluations of data were performed using Student's unpaired $t$-test. Statistical analysis was performed using SPSS 20.0 software (SPSS, Inc., Chicago, IL, USA). A value of $p<0.05$ was considered statistically significant.

\section{Results}

Characterization of PTX-PEG-PLA-NP and PTX-PEG-PLA-FA-NP Figure $1 \mathrm{a} / \mathrm{b}$ represents the HNMR feature of PEG-PLANP and PEG-PLA-FA-NP. It shows that there was a peak at $2.60 \mathrm{ppm}$ in PEG-PLA-FA-NP compared to PEG-PLANP, which successfully confirmed that FA was linked to PEG-PLA-NP. The particle sizes were $167.54 \pm 13.80 \mathrm{~nm}$ for PTX-PEG-PLA-NP, as shown in Fig. 1c, and $192.32 \pm$ $21.33 \mathrm{~nm}$ for PTX-PEG-PLA-FA-NP, as seen in Fig. 1d. Figure 1e shows the particle size of two different nanoparticles, there is no statistically significant of the two types of nanoparticles $(P>0.05)$. Figure $1 f$ shows the TEM images of the nano-carriers, which were well separated, spherical in shape, and had a smooth surface. The ZP values in two kinds of PTX-NPs were $-39.81 \pm 3.45 \mathrm{mV}$ and $-18.47 \pm 1.45 \mathrm{mV}$, respectively. The EE was approximately $73.75 \%$ for PTX-PEG-PLA-NP and $81.50 \%$ for PTX-PEG-PLA-FA-NP, while the amounts of DL were $12.29 \%$ and $5.42 \%$, respectively.

\section{Drug release profiles of nano-carriers}

As shown in Fig. 2a, the drug release rates of the two nano-carriers were $6.98 \%$ and $5.44 \%$, which were much less than that of the free PTX solution (10.84\%) at $4 \mathrm{~h}$. Moreover, the cumulative release rate of PTX in the free PTX solution increased markedly after $4 \mathrm{~h}$ compared with the two PTX-NP groups, which indicated that nanocarriers had the advantage of drug slow-release effect.

\section{Pharmacokinetic features of different groups}

Standard curves were established for calculating the PTX concentrations in various tissues and plasma. Linear regression analysis provided the linear regression equation between the PTX concentration (X) and AUC (Y) (Table 1). Pharmacokinetic features are shown in Fig. $2 \mathrm{~b}$. The elimination phases $\left(t_{1 / 2, \beta}\right)$ of PTX-PEG-PLA-FA-NP and PTX-PEG-PLA-NP (15.92 $\mathrm{h}$ and $13.47 \mathrm{~h}$, respectively) were much longer than those of the free PTX (6.41 h, $p<0.05)$. The AUC was $159.81 \mu \mathrm{g} / \mathrm{ml} / \mathrm{h}$ for PTX-PEG-PLA-NP and $132.72 \mu \mathrm{g} / \mathrm{ml} / \mathrm{h}$ for PTX-PEGPLA-FA-NP $(p>0.05)$, which were both approximately 3 -fold greater than the free PTX $(52.65 \mu \mathrm{g} / \mathrm{ml} / \mathrm{h}, p<0.05)$. Based on these results, the PTX loaded into the nanocarriers was cleared much more slowly than the free PTX in blood circulation. The slow-release effect of the nanocarriers was proved again in addition to the results of the drug release study.

\section{Expression levels of FARa in ovarian cancer cell lines}

As shown in Fig. 3b, the FAR $\alpha$ levels in the SK-OV-3 cells $(79.91 \pm 9.78)$ were much higher than in the other two cells HO-8910 (66.71 \pm 5.23$)$ and A2710 (1.00 \pm $0.05)(p<0.05)$. Based on this result, SK-OV-3 was used in the following experiments.

\section{Cellular uptake results in vitro}

As shown in Additional file 2: Figure S1, we normalized the FITC fluorescence to DAPI to test the different cellular densities of different cell types in the cell uptake experiment. The results showed that there were no statistical difference among groups $(p>0.05)$, which indicated that the number of cells in each group was the same. As shown in Fig. 3a, the SK-OV-3 cells took up more PEG-PLA-FA-NP than PEG-PLA-NP. In addition, more PEG-PLA-FA-NP was taken up by the SK-OV-3 cells than the HO-8910 and A2780 cells. The fluorescence intensity of PEG-PLA-NP in three ovarian cancer cell lines (A2780, HO-8910, and SK-OV-3) were $12.62 \pm 2.63$ a.u., $34.58 \pm 6.22$ a.u., and $29.19 \pm 7.63$ a.u. $(p>0.05)$, respectively. In the PEG-PLA-FA-NP group, the fluorescence intensities were $20.83 \pm 6.27$ a.u., $40.56 \pm$ 13.44 a.u., and $61.245 \pm 1.47$ a.u. $(p<0.05)$, respectively. In the SK-OV-3 cells, the fluorescence intensity of PEGPLA-FA-NP was much higher than PEG-PLA-NP, as 

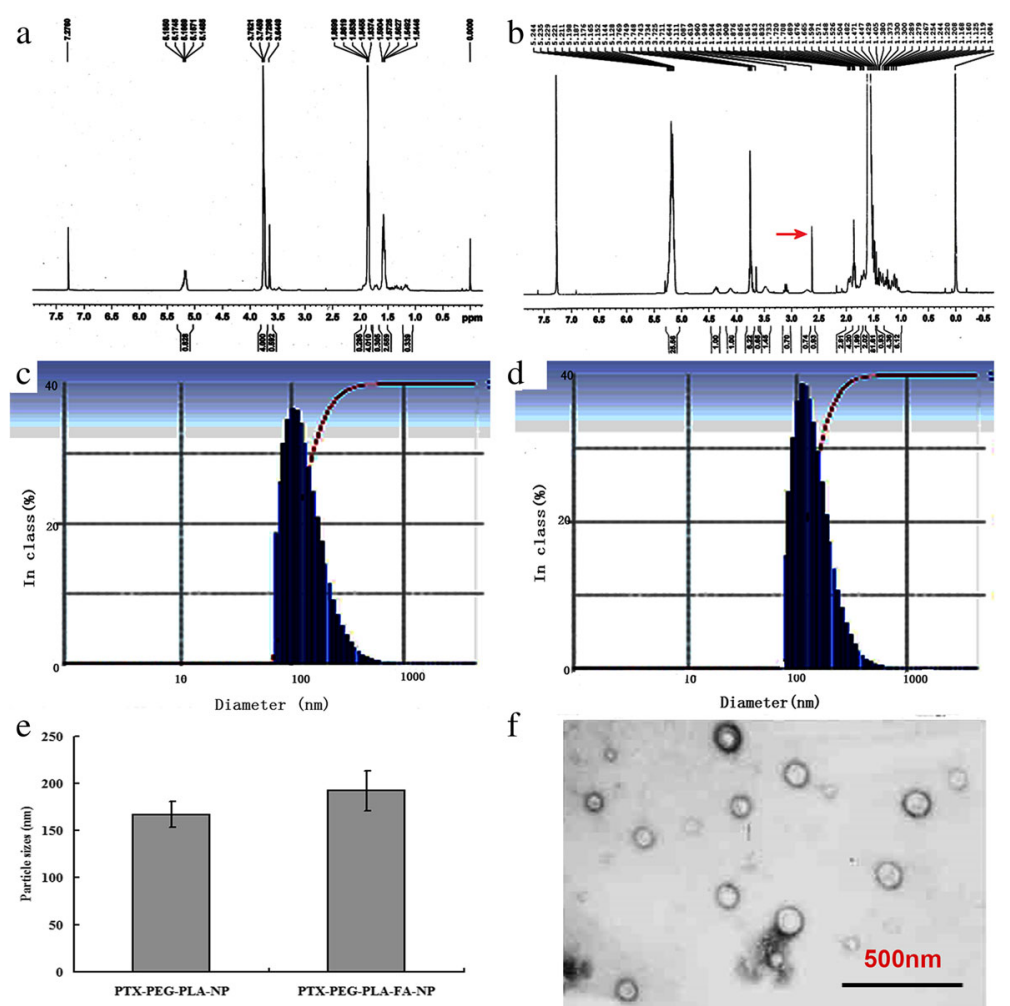

f

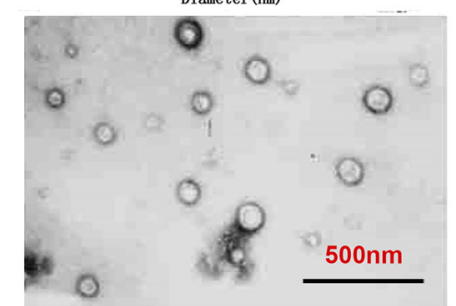

Fig. 1 The characterization of PTX-PEG-PLA-NP and PTX-PEG-PLA-FA-NP. Notes: (a) HNMR (Nuclear Magnetic Resonance) image of PEG-PLA-NP; (b) HNMR image showed that PEG-PLA-FA-NP owned an obvious peak at 2.60 ppm, which indicated that FA was linked to PEG-PLA-NP; (c/d) Particles size distribution pattern of PTX-PEG-PLA-NP and PTX-PEG-PLA-FA-NP; (e) Particles sizes of two kinds of nano-carriers; (f) TEM images of PTX-NP, which was well separated, spherical in shape and with smooth surface

shown in Fig. 3c, while in the other two cancer cell lines, there were no statistical differences between the two groups $(p>0.05)$. Figure $3 \mathrm{~d}$ shows that the fluorescence intensity peaked at $4 \mathrm{~h}$ in all three kinds of cancer cells. Figure 3e shows that in the SK-OV-3 cells, the PEG-PLAFA-NP solution with $10 \%$ FA had greater uptake than both 5\% FA and 20\% FA. Based on these results, PEGPLA-FA-NP-based tumor-targeting characteristics were confirmed in vitro, and several parameters such as the SKOV-3 cells, $4 \mathrm{~h}$ after drug delivery, and 10\% FA contents were used in the following experiments. Figure $3 \mathrm{f}$ shows the cellular uptake results of PTX-PEG-PLA-FA-NP in SKOV-3 cells in different concentration FA contained culture medium $(0 \mu \mathrm{g} / \mathrm{ml}, 5 \mu \mathrm{g} / \mathrm{ml}, 20 \mu \mathrm{g} / \mathrm{ml}$ and $50 \mu \mathrm{g} / \mathrm{ml})$ by fluorescence microscopy; The images showed that more PTX-PEG-PLA-FA-NP was taken up by SK-OV-3 cells in the FA-free culture medium. With FA concentration increase from $5 \mu \mathrm{g} / \mathrm{ml}$ to $50 \mu \mathrm{g} / \mathrm{ml}$ the fluorescence signals in the SK-OV-3 cells decreased accordingly, with suggested that PTX-PEG-PLA-FA-NP uptake were FAR-specific on SK-OV-3 cells; Fig. 3g shows the fluorescence intensity of PTX-PEG-PLA-FA-NP in SK-OV-3 cells with different concentration FA contained culture medium $(0 \mu \mathrm{g} / \mathrm{ml}$, $5 \mu \mathrm{g} / \mathrm{ml}, 20 \mu \mathrm{g} / \mathrm{ml}, 50 \mu \mathrm{g} / \mathrm{ml})$.

\section{Cellular cytotoxicity of nano-carriers in vitro}

Figure 4a shows that up to a concentration of $100 \mu \mathrm{g} / \mathrm{ml}$, PEG-PLA-NP did not obviously inhibit the SK-OV-3 cells, with a relative cell viability rate of $80 \%$, which confirmed the hypotoxicity of PEG-PLA-NP. Figure $4 \mathrm{~b}$ indicates that PTX-PEG-PLA-FA-NP had more cytotoxicity against the SK-OV-3 cells at multiple dosages than the other two groups given the same PTX concentrations (co-incubated for $24 \mathrm{~h})(p<0.05)$. However, PTX-PEG-PLA-NP showed an equivalent inhibitory efficacy to free PTX $(p>0.05)$. For example, at a PTX dose of $50 \mu \mathrm{g} / \mathrm{ml}$, the cell inhibition rates were $0.15 \pm 0.05,0.36 \pm 0.05$, and $0.53 \pm 0.04$ in the PTX, PTX-PEG-PLA-NP, and PTX-PEG-PLA-FA-NP groups, respectively $(p<0.05)$. Once loaded into PEGPLA-FA-NP, only a half dose of PTX could achieve the same toxicity as the full dose of free PTX. Figure 4c shows that the toxicities of the three different groups (PTX concentration was $50 \mu \mathrm{g} / \mathrm{ml}$ ) were time-dependent and the cytotoxicity peaked $48 \mathrm{~h}$ after drug delivery.

\section{Tissue-distribution results of PTX in different groups}

The PTX levels in plasma and other tissues at different time points after drug delivery are shown in Fig. 5. First, the peak reach times were extended in both nano-carrier 

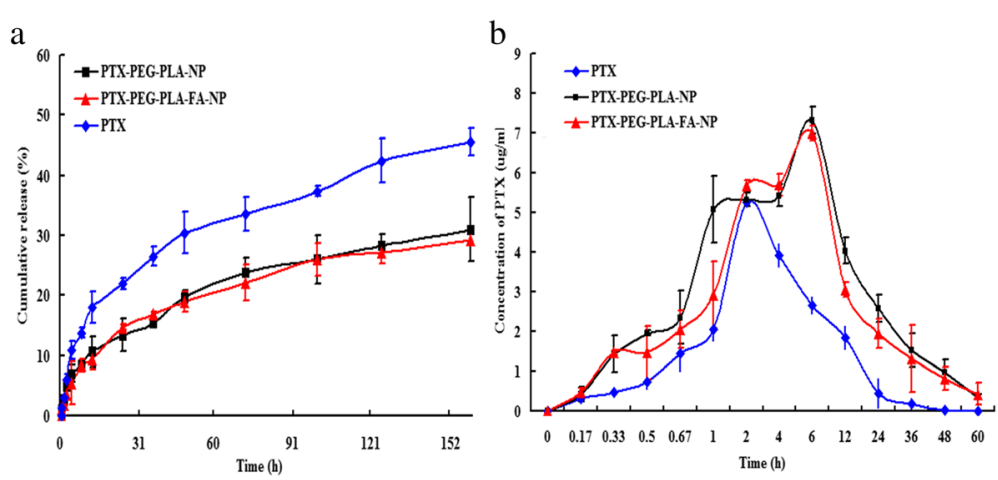

Fig. 2 The release profiles and the pharmacokinetics features of different groups. Notes: (a) The drug release profiles of free PTX solutions, PTX-PEG-PLA-NP and PTX-PEG-PLA-FA-NP. The PTX cumulative release rate in free PTX group increased markedly over that of other two PTX-NP groups after $4 \mathrm{~h}$, which indicated that the nano-carriers exhibited delayed drug release; (b) The pharmacokinetics results in different drug groups. The elimination phase $\left(t_{1 / 2, \beta}\right)$ of PTX-PEG-PLA-NP and PTX-PEG-PLA-FA-NP solutions (13.47 $\mathrm{h}$ and $15.92 \mathrm{~h}$ ) were much longer than that of PTX solution (6.41 h, $p<0.05)$. The AUC was $159.81 \mu \mathrm{g} / \mathrm{ml} / \mathrm{h}$ for PTX-PEG-PLA-NP and $132.72 \mu \mathrm{g} / \mathrm{ml} / \mathrm{h}$ for PTX-PEG-PLA-FA-NP, which were both approximately three-fold greater than that of free PTX $(52.65 \mu \mathrm{g} / \mathrm{ml} / \mathrm{h})$

groups $(6 \mathrm{~h})$ compared to the free PTX group $(2 \mathrm{~h})$ in all tissues, including the tumor tissue, as shown in Fig. 6 a. These results once again confirmed the slow-release effect of nano-carriers similar to the pharmacokinetics study results. Second, in tumor tissues, the PTX concentrations in the PTX-PEG-PLA-FA-NP group (15.27 \pm $0.48 \mu \mathrm{g} / \mathrm{ml}$ ) at $6 \mathrm{~h}$ after drug delivery were much higher than in the free PTX $(4.66 \pm 0.36 \mu \mathrm{g} / \mathrm{ml}, p<0.05)$ and PTX-PEG-PLA-NP groups $(5.88 \pm 0.67 \mu \mathrm{g} / \mathrm{ml}, p<0.05)$, as shown in Fig. 6b, while there was no statistical difference between the latter two groups. We also obtained the same results at other time points. All these results indicated the tumor-targeting characteristic of PTXPEG-PLA-FA-NP based on FA-mediated active targeting. Third, except for the liver, uterus, and tumor tissues, PTX-PEG-PLA-NP had greater uptake than in the PTXPEG-PLA-FA-NP group by other tissues at most time points. Interestingly, the PTX concentration was at low levels in the kidney, heart, lungs, and small intestine in the PTX-PEG-PLA-FA-NP group compared to the liver and uterine tissues.

Table 1 Linear equation of PTX in plasma and other tissues

\begin{tabular}{lll}
\hline Tissues & Linear equation & $R^{2}$ \\
\hline Liver & $Y=220.198 X+273.685$ & 0.991 \\
Kidney & $Y=314.886 X+243.909$ & 0.998 \\
Plasma & $Y=282.057 X+56.232$ & 0.999 \\
Heart & $Y=241.086 X+395.958$ & 0.995 \\
Spleen & $Y=312.948 X+288.311$ & 0.994 \\
Lung & $Y=220.198 X+273.685$ & 0.997 \\
Intestine & $Y=267.209 X+460.006$ & 0.998 \\
Ovary & $Y=312.655 X+279.929$ & 0.996 \\
Tumor & $Y=304.006 X+49.557$ & 0.997 \\
\hline
\end{tabular}

Therapeutic anti-tumor effects of different groups in vivo The final tumor sizes in the treated mice were notably reduced in the PTX-PEG-PLA-FA-NP group, as seen in Fig. $7 \mathrm{~b}$, while there was no statistical difference between the free PTX and PTX-PEG-PLA-NP groups $(p>0.05)$. The final tumor size in the PTX-PEG-PLA-FA-NP group was $477.89 \pm 4.66 \mathrm{~mm}^{3}$, which was much smaller than in the PTX-PEG-PLA-NP $\left(591.89 \pm 9.37 \mathrm{~mm}^{3}, \quad p<0.05\right)$ and free PTX $\left(608.38 \pm 6.05 \mathrm{~mm}^{3}, p<0.05\right)$ groups as well as the control group $\left(822.31 \pm 43.10 \mathrm{~mm}^{3}, p<0.05\right)$. All treatment groups exhibited obvious anti-tumor effects compared to the control group $(p<0.05)$. The tumor growth curve showed that the PTX-PEG-PLAFA-NP group had a much stronger anti-tumor effect than the other groups, as shown in Fig. 7c. The tumor inhibitory rates based on tumor volume were $41.88 \%$ in the PTX-PEG-PLA-FA-NP group, which was around 1.5 times higher than in the PTX-PEG-PLA-NP (28.02\%) and free PTX groups (25.99\%). Figure 7d shows the body weight changes of the animals. There was no significant difference among the four groups $(p>0.05)$, which indicated that there were no obvious side effects in the nano-carriers group.

\section{Discussion}

In this study, we developed a novel active-targeting drug-delivery system, PTX-PEG-PLA-FA-NP, which is a potential effective and promising therapeutic strategy for cancer treatment. Polylactic acid (PLA) is a synthetic biodegradable polymer that has been approved by the U.S. Food and Drug Administration (FDA) for medical applications [18, 19]. However, because of its weak hydrophilicity, excessively long degradation time, and low drug loading of polar drugs [20, 21], PLA's applications are limited. To overcome these shortcomings, PEG 


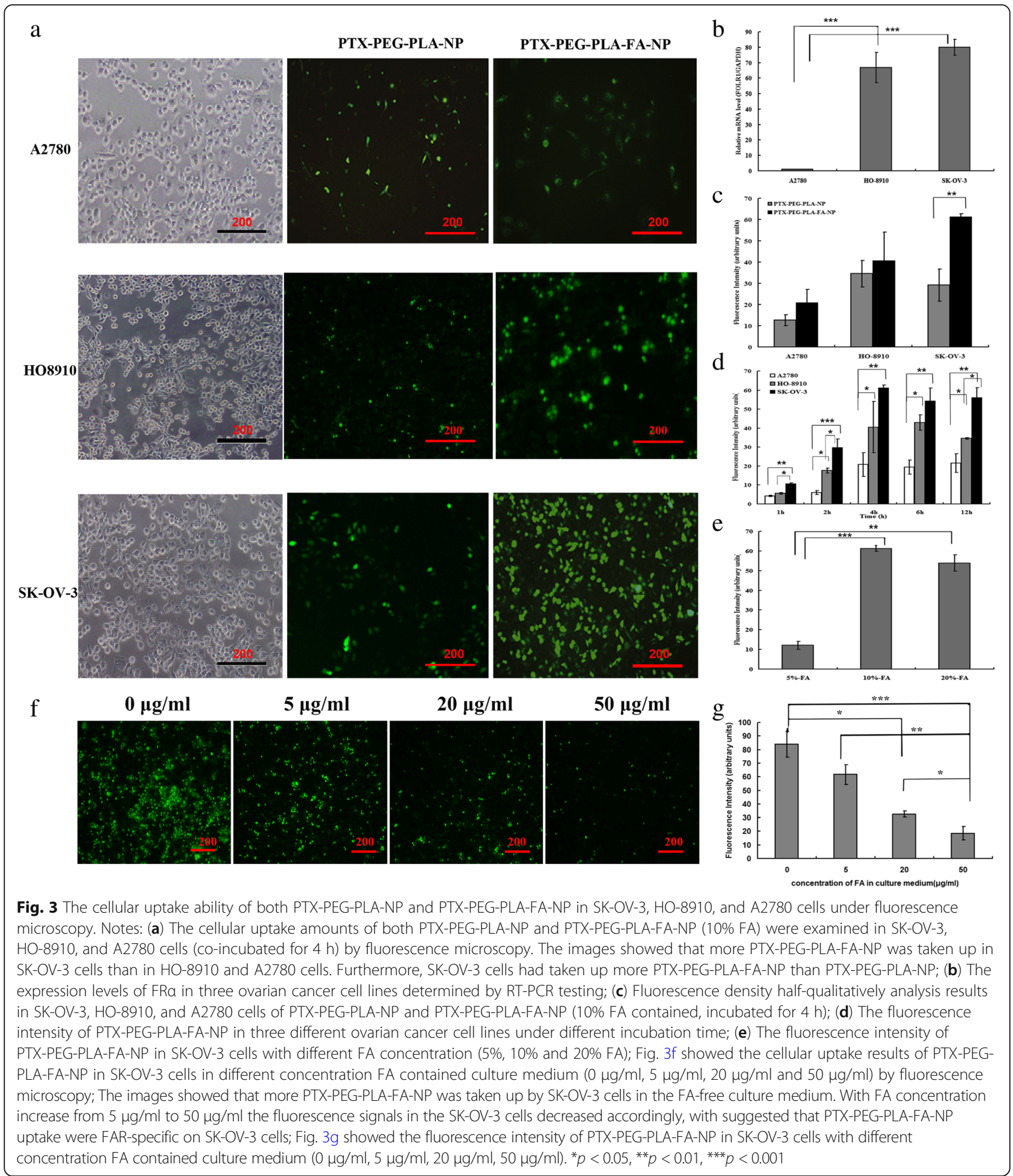

was combined with PLA to form a block co-polymer in this study [22-24]. Most kinds of cancer including ovarian cancer over-express FA receptor, and FA was demonstrated to be an excellent tumor-targeting molecule in nano-carrier drug delivery systems $[25,26]$. In this study, we attached the FA molecule to the PEG-PLA block co-polymer by covalent bonding between the hydroxyl of the FA molecule and the N-terminal of PEG-PLA and eventually developed the PTX-loaded active tumortargeting drug-delivery system PTX-PEG-PLA-FA-NP.

Paclitaxel is usually solubilized in polyoxyethylene castor oil (Cremophor EL) and ethanol (1: 1) for clinical 


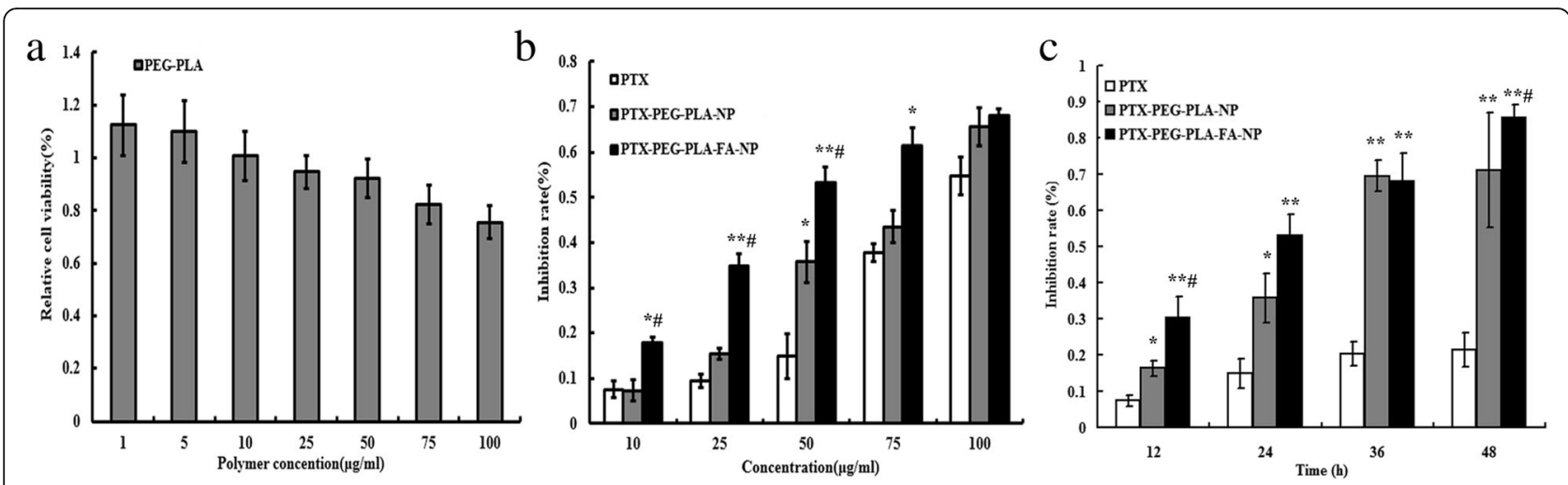

Fig. 4 The cellular toxicity of two kinds of nano-carriers in vitro. Notes: (a) The toxicity of the blank PEG-PLA-NP to SK-OV-3 cells. Up to the concentration of $100 \mu \mathrm{g} / \mathrm{ml}$, blank nano-carriers did not inhibit the SK-OV-3 cells viability significantly; (b) The cellular inhibition rate in different groups. PTX-PEG-PLAFA-NP showed significantly more toxicity against SK-OV-3 cells at multiple dosages than PTX-PEG-PLA-NP as well as free PTX based on the equivalent PTX concentrations $(p<0.05)$. (c)The toxicity to SK-OV-3 cells under different co-incubation intervals. ${ }^{*} p<0.05,{ }^{* *} p<0.01,{ }^{* * *} p<0.001$ vs PTX. ${ }^{*} p<0.05$, \# \# $p<0.01$, \# \# $p<0.001$ vs PTX-PEG-PLA-NP

application because of its poor hydrophilicity [27, 28], which frequently induces anaphylactic shock. In this study, PTX was loaded into the nano-carriers, and the problem of poor hydrophilicity and anaphylactic response was thus resolved. This was one of the advantages of our PEG-PLA-FA-NP drug-delivery system.

Another advantage of our nano-delivery system was its perfect slow-release effect. The drug release study, the pharmacokinetic study, and the drug-distribution study results demonstrated that PTX loaded into nano-carriers could be sustained for a much longer time (the prolonged $t_{1 / 2}$ and peak reach time) in the body circulation than the free PTX solutions. In other words, given the same drug dose, nano-carriers could make PTX more effective against tumors.

The most important advantage of our nano-delivery system was its active targeting characteristic of tumor tissues. In contrast to FA-free PTX-PEG-PLA-NP, PTXPEG-PLA-FA-NP had greater uptake by SK-OV-3 cells in vitro. A drug distribution study of tumor-bearing animals showed that the PTX concentration in tumor tissues in the PTX-PEG-PLA-FA-NP group was 3 times higher than in the FA-free PTX-PEG-PLA-NP and PTX groups. One possible reason is that the FA molecule can be recognized by the FA receptor on the surface of the cancer cells and induces receptor-mediated endocytosis, which is supposed to be the basic theory of the active tumor-targeting effect of PTX-PEG-PLA-FA-NP. Another reason for this difference might contribute to the enhanced permeability and retention (EPR) effect of nano-carriers in the body's circulation [29]. A schematic illustration of tumor targeting was shown in Fig. 8. Figure 9 indicated that the flowchart of tissuedistribution study in vivo. There are also many other factors affecting the distribution of nano-carriers in vivo, such as the target organ type, the nano-carriers' size, and the surface charges of the nano-carriers [30].

The excellent slow-release effects and tumor-targeting characteristics significantly enhanced the anti-tumor efficiency of PTX-PEG-PLA-FA-NP for ovarian cancer, which was also confirmed in this study. PTX-PEG-PLAFA-NP was proved to be more toxic to SK-OV-3 cells in vitro at different dosages than PTX-PEG-PLA-NP and PTX. Compared to free PTX solutions, half-dose PTX in PTX-PEG-PLA-FA-NP could achieve the same toxicity to cells. In tumor-bearing animals, the tumor inhibitory rate was $41.88 \%$ in the PTX-PEG-PLA-FA-NP group, which was approximately 1.5 times higher than that in the PTX-PEG-PLA-NP (28.02\%) and free PTX groups (25.99\%). All these results confirmed that PTX-PEGPLA-FA-NP could significantly enhance the anti-tumor effects of PTX, which should contribute to the selective accumulation of PTX in cancer cells and tissues using a PTX-loaded nano-delivery system. Zhang et al. used FSH33 as a targeting molecule and prepared PTXloaded FSH33-PEG-PLA-NP, which showed tumortargeting effects and nano-carrier-mediated toxicity only in vitro [31]. In our study, the pharmacokinetics analysis was done in Sprague-Dawley rats while the anti-tumor efficacy of the nano-carriers was determined using mice, there are two main reasons for using two different animal species. Firstly, There are two advantages that Sprague-Dawley rats as the animal model for pharmacokinetics analysis: 1. Nanoparticle solutions could be injected to Sprague-Dawley rats more easily through the tail vein than mice. 2. The pharmacokinetics analysis need the drug concentrations in blood at different time points. Sprague-Dawley rats have enough plasma to accomplish all time points experiment. So we choose Sprague-Dawley rats to do the pharmacokinetics study 


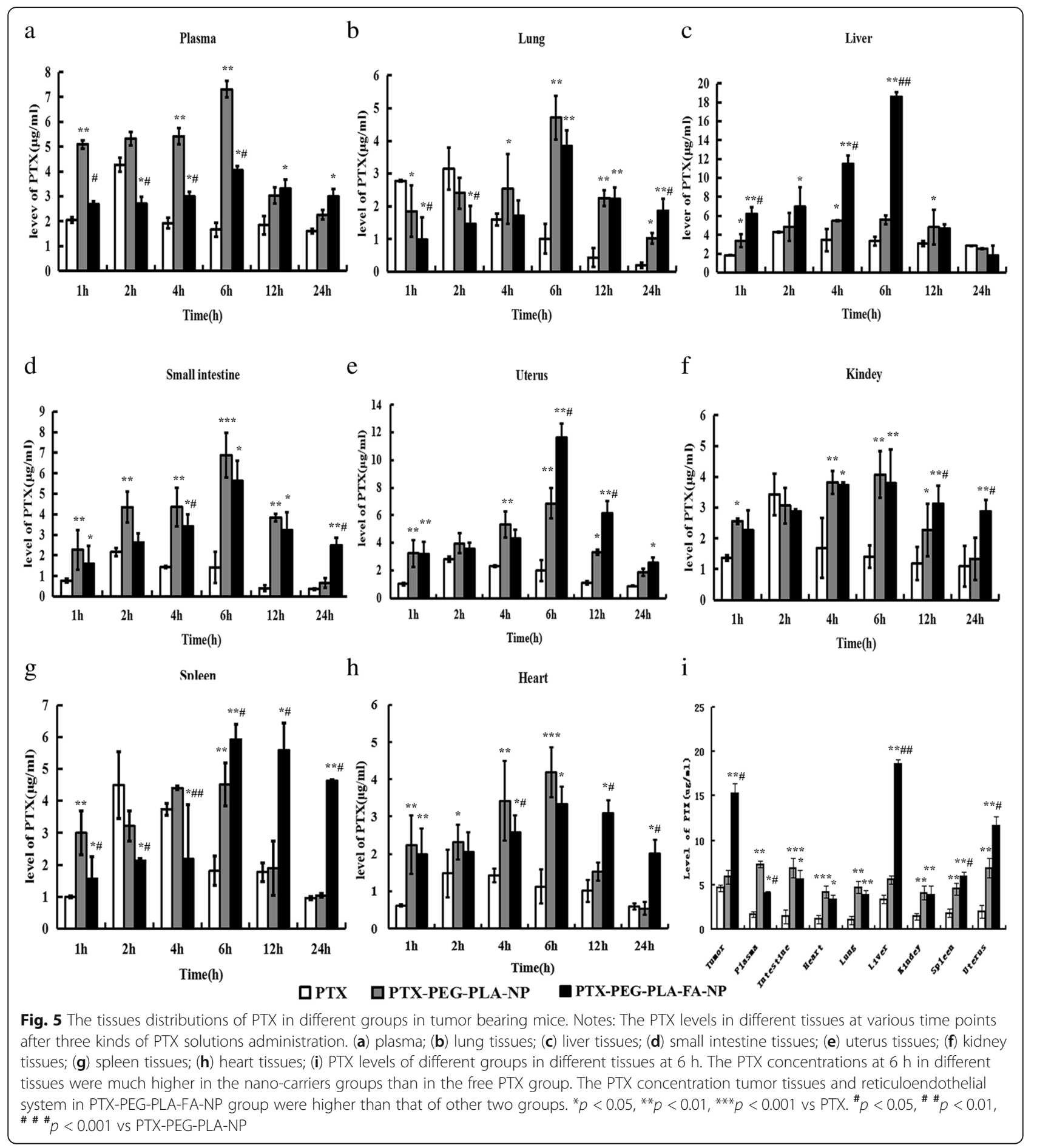

in vivo [32]. Secondly, in our study, we need tumorbearing animal models to perform the drug distribution study and the anti-tumor experiment. Nude mice is immunodeficiency and thus suitable for tumor transplantation. So in this study, we choose nude mice to perform the drug distribution study and the anti-tumor effect experiment in vivo [33].
In our study, we confirmed the slow-release effect, tumor-targeting characteristics, and enhanced anti-tumor effects both in vitro and in vivo using an FA-enhanced PTX-PEG-PLA-NP drug-delivery system. Our study results offered more convincing evidence to support the application of nano-delivery systems against cancer. Conversely, we also found that more drugs could accumulate in the 
a

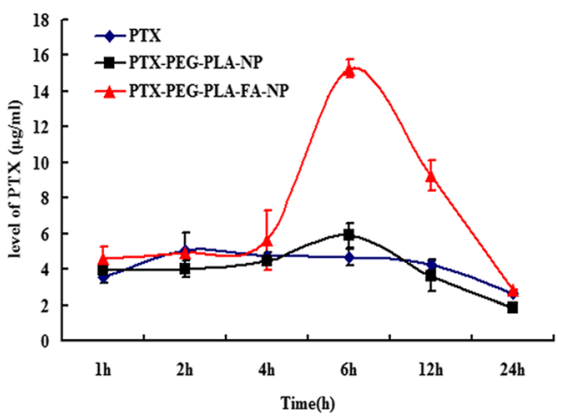

b

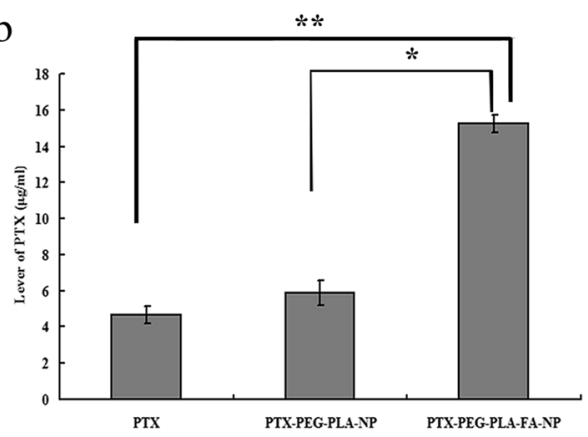

Fig. 6 The tissue distributions of PTX in tumor tissues in different drug groups. Notes: The PTX levels in tumor tissues at various time points after drug delivery by three kinds of PTX solutions. (a) The PTX concentration of three groups in tumor tissues; (b) The PTX concentration in tumor tissues at $6 \mathrm{~h}$. The PTX concentrations at various time points were much higher in the PTX-PEG-PLA-FA-NP group than free PTX and FA-free nano-carriers group, which suggested that the PTX-PEG-PLA-FA-NP could accumulate selectively in tumor tissues. For example, the PTX level in the PTX-PEG-PLA-FA-NP group at $6 \mathrm{~h}(15.267 \pm 0.475 \mu \mathrm{g} / \mathrm{ml})$ was much higher than that of PTX-PEG-PLA-NP group $(5.883 \pm 0.674 \mu \mathrm{g} / \mathrm{ml})$ and PTX group $(4.663 \pm 0.357 \mu \mathrm{g} / \mathrm{ml})(p<0.05) .{ }^{*} p<0.05,{ }^{* *} p<0.01,{ }^{* * *} p<0.001$

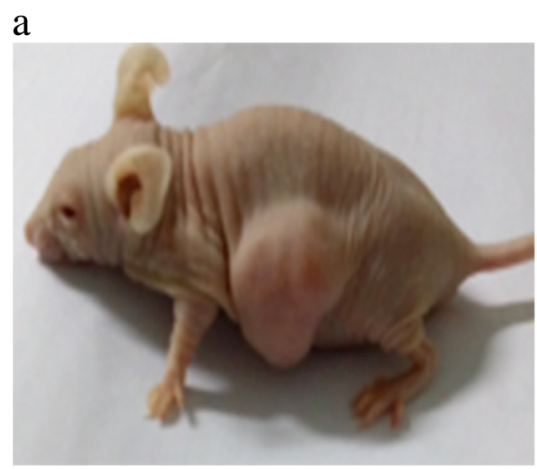

C

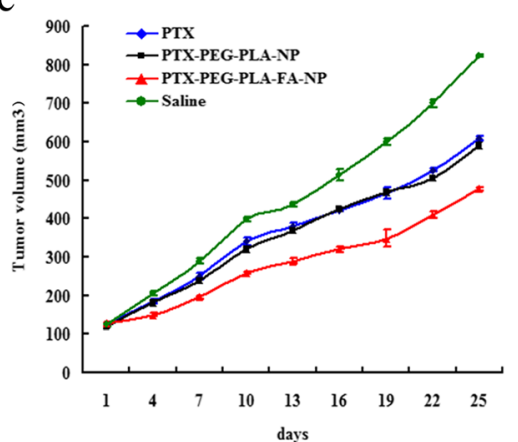

b

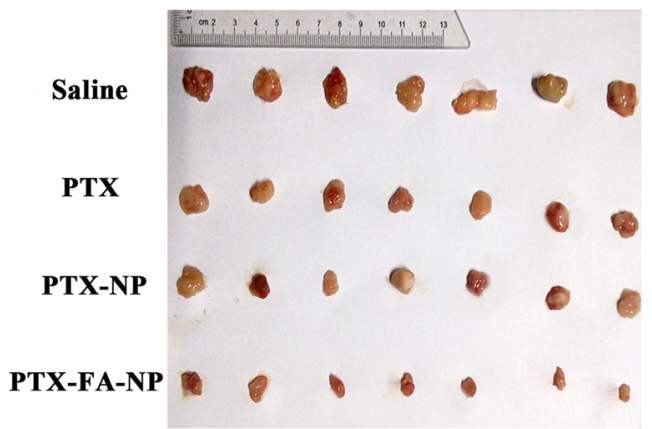

d

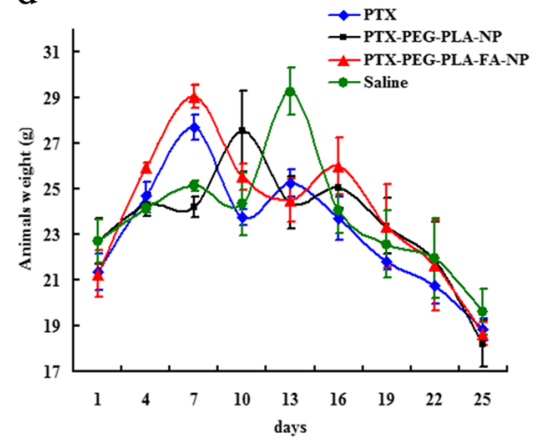

Fig. 7 Anti-tumor effect of free PTX, PTX-PEG-PLA-NP and PTX-PEG-PLA-FA-NP solutions to the nude mice with subcutaneous tumor. Notes: (a) Established subcutaneous tumor models in nude mice; (b) Tumor tissues removed from the mice at the end point in different groups; (c) Tumor growth curves throughout the whole experiment. The inhibitory rates was $41.88 \%$ in the PTX-PEG-PLA-FA-NP group, which was 1.5 times higher than that in PTX-PEG-PLA-NP group (28.02\%) and free PTX group (25.99\%); (d) Body weight change of tumor-bearing mice. There was no significant difference in the average body weights among four groups $(p>0.05)$, which means no obvious side effects of nano-carriers system 


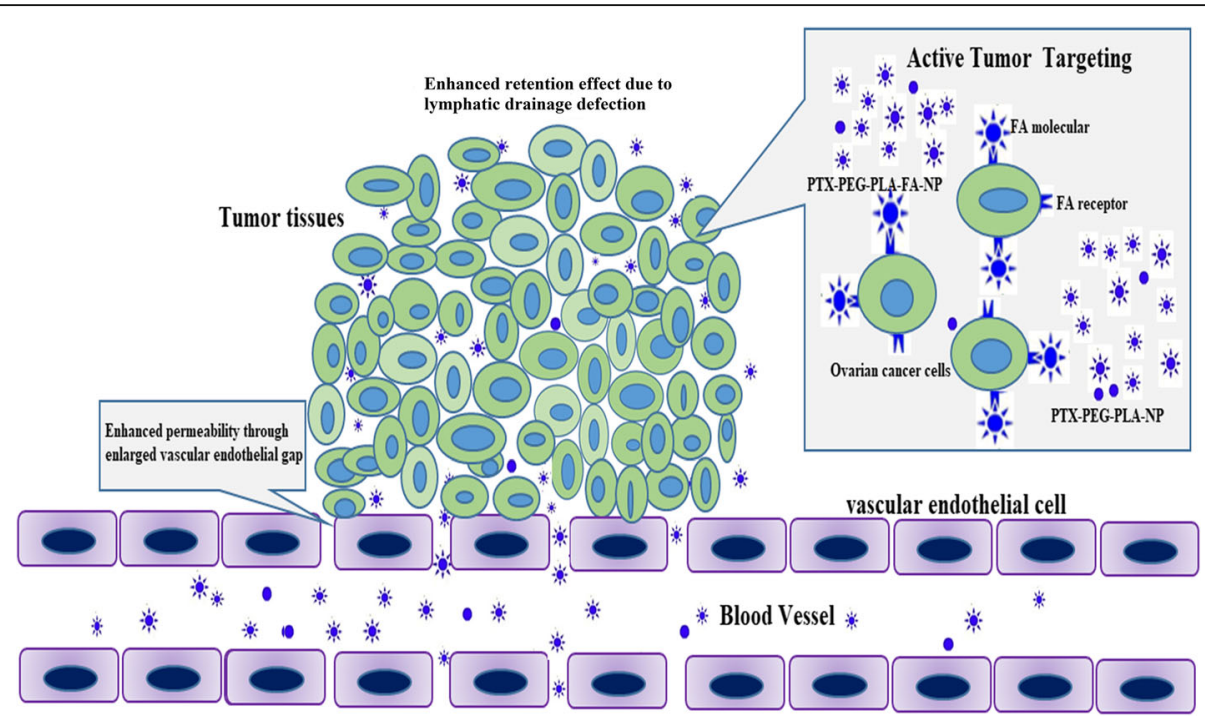

Fig. 8 The schematic illustration of tumor targeting. Notes: This figure showed FA mediated active tumor-targeting mechanism and EPR effect

reticuloendothelial system (RES) organs. This indicated that we should pay more attention to the side effects of chemotherapy on RES organs when a nano-delivery system is used [34].

\section{Conclusion}

In summary, this comprehensive study consisted of: (1) the preparation and characterization testing of nano- carriers, (2) the slow-release effect verification in vitro and in vivo, (3) the tumor-targeting characteristics verification in vitro and in vivo, and (4) the antitumor effect verification in vitro and in vivo. All these results showed that the PTX-PEG-PLA-FA-NP nano-delivery system had improved hydrophilicity, slow-release effects, low toxicity, and tumor-targeting characteristics. More drugs could be delivered into tumor tissues selectively and accordingly

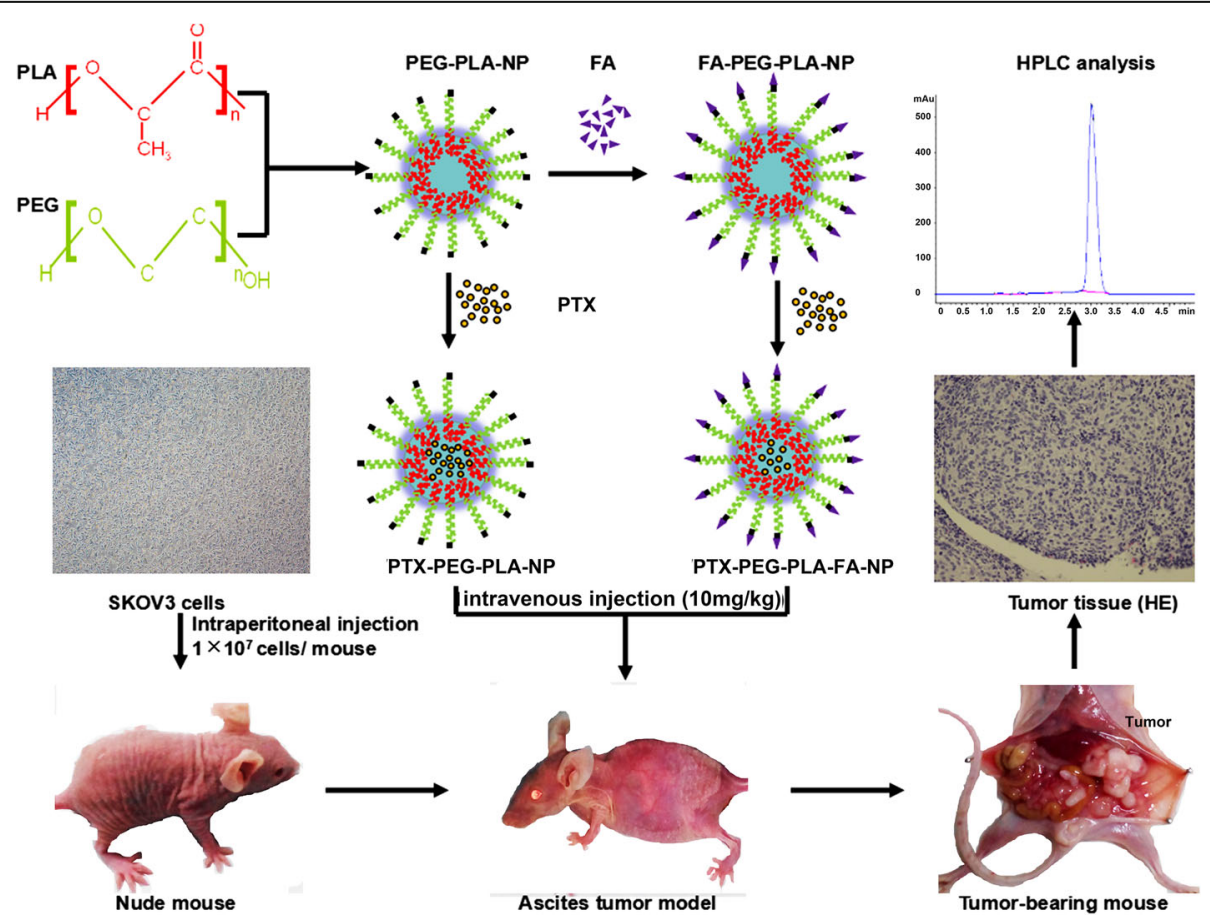

Fig. 9 The flowchart of tissue-distribution study in vivo 
and the anti-tumor effect was enhanced significantly using this nano-delivery system. PTX-PEG-PLA-FA-NP-based therapy should be a promising new treatment strategy for ovarian cancer patients in the future.

\section{Additional files}

Additional file 1: STR for A2780, SK-OV-3 and HO-8910 cells. (DOC 75 kb)

Additional file 2 DAPI fluorescence density of two nanocarriers in three different ovarian cancer cell lines. (PNG 971 kb)

\begin{abstract}
Abbreviations
AUC: Area under the curve; DCM: Dichloromethane; DLS: Dynamic light scatting; EO: Epoxy ethane; EPR: Enhanced permeation and retention; FA: Folic acid; FBS: Fetal bovine serum; HNMR: Nuclear magnetic resonance spectroscopy; HPLC: High performance liquid chromatography; KHMDS: potassium bis (trimethylsilyl) amide; M-mIV: moloney-murine leukemia virus; MTT: (3-[4,5-dimethylthiazol-2-yl]-2,5-diphenyltetrazolium bromide; NP: Nanoparticles; PBS: Phosphate-buffered saline; PEGPLA: Polyethylene glycol and polylactic acid; PTX: Paclitaxel; RES: Reticuloendothelial system; TEM: Transmission electron microscopy; THF: Tetrahydrofuran; ZP: Zeta potential
\end{abstract}

\section{Acknowledgments}

The authors acknowledge that the Department of Obstetrics and Gynecology at Shandong University provided key laboratory facilities and funds for this research. This work was supported by the National Science Foundation of China (81172488) and the Fundamental Research Funds of Shandong University (2014QLKY24).

\section{Authors' contributions}

$\mathrm{KS}$ is full responsible for the study designing, experiment adjustment. BK is responsible for supervise the whole experiment. SY and XS conducted the experiments and wrote the first draft of the manuscript. ZL and KW prepared the nanoparticles and drafted the method of the preparation. LL contributed to animal experiment in vivo. CY and SY carried out animal experiment, cell experiment in vitro, statistical analysis and the supervised experimental work. JF carried out the MTT assay, uptaken experiment and toxicity study of nanoparticles. All authors read and approved the final manuscript.

\section{Competing interests}

The authors declare that they have no competing interests. We confirm that the manuscript has been read and approved by all named authors and that there are no other persons who satisfied the criteria for authorship but are not listed in the manuscript has been approved by all of us. We further confirm that any aspect of the work covered in this manuscript involved experimental animals has been conducted with the ethical approval of all relevant bodies and that such approvals are acknowledged within the manuscript.

\section{Publisher's Note}

Springer Nature remains neutral with regard to jurisdictional claims in published maps and institutional affiliations.

\section{Author details}

'Department of Obstetrics and Gynecology, Qilu Hospital, Shandong University, 107 Wenhua Xi Road, Jinan, Shandong 250012, People's Republic of China. ${ }^{2}$ Gynecology Oncology Key Laboratory, Qilu Hospital, Shandong University, Jinan, Shandong 250012, China. ${ }^{3}$ Department of Biomedical Engineering, School of Control Science and Engineering, Shandong University, Jinan, Shandong 250012, China. ${ }^{4}$ Department of Chemistry and Chemical Engineering, Shandong University, Jinan, Shandong 250012, China.
Received: 12 October 2017 Accepted: 7 February 2018

Published online: 26 February 2018

\section{References}

1. Brett MR, Jennifer BP, Thomas AS. Epidemiology of ovarian cancer: a review. Cancer Biol Med. 2016;0084:9-32.

2. Li Z, Sun LP, Lu ZJ, Su XT, Yang QF, Qu X, et al. Enhanced effect of photodynamic therapy in ovarian cancer using a nanoparticle drug delivery system. Int J Oncol. 2015;47:1070-6.

3. Siegel RL, Miller KD, Jemal A. Cancer statistics, 2017. CA Cancer J Clin. 2017:67:7-30

4. Huang L, Cronin KA, Johnson KA, Mariotto AB, Feuer EJ. Improved survival time: what can survival cure models tell us about population-based survival improvements in late-stage colorectal, ovarian, and testicular cancer? Cancer. 2008;112:2289-300.

5. Keith LK, Lavakumar K, Purushottam L, Claudia P. Targeted immune therapy of ovarian cancer. Cancer Metastasis Rev. 2015;34:53-74.

6. Sengupta S, Eavarone D, Capila I, Zhao G, Watson N, et al. Temporal targeting of tumour cells and neovasculature with a nanoscale delivery system. Nature. 2005;436:568-72.

7. Howes PD, Chandrawati R, Stevens MM. Colloidal nanoparticles as advanced biological sensors. Science. 2014;346(6205)

8. Wicki A, Witzigmann D, Balasubramanian V, Huwyler J. Nanomedicine in cancer therapy: challenges, opportunities, and clinical applications. J Control Release. 2015;200:138-57.

9. Vergote I, Finkler NJ, Hall JB, Melnyk O, Edwards RP, Jones M, et al. Randomized phase III study of canfosfamide in combination with pegylated liposomal doxorubicin compared with pegylated liposomal doxorubicin alone in platinum-resistant ovarian cancer. Int J Gynecol Cancer. 2010;20:772-80

10. Mutch DG, Orlando M, Goss T, Teneriello MG, Gordon AN, McMeekin SD, et al. Randomized phase III trial of gemcitabine compared with pegylated liposomal doxorubicin in patients with platinum-resistant ovarian cancer. J Clin Oncoly. 2007;25:2811-8.

11. Marchetti C, Palaia I, Giorgini M, De MC, ladarola R, Vertechy L, et al. Targeted drug delivery via folate receptors in recurrent ovarian cancer: a review. OncoTargets Ther. 2014;7:1223-36.

12. Elnakat $H$, Ratnam M. Role of folate receptor genes in reproduction and related cancers. Front Biosci. 2006;11:506-19.

13. Chen YL, Chang MC, Huang CY, Chiang YC, Lin HW, Chen CA, et al. Serous ovarian carcinoma patients with high alpha folate receptor had reducing survival and cytotoxic chemo-response. Mol Oncol. 2012;6:360-9.

14. Miriana H, Soumen D, Ismail M, Ankur G, Zaid AW, Calvin T, et al. Folic acid tagged nanoceria as a novel therapeutic agent in ovarian cancer. BMC Cancer. 2016;16:220-30.

15. Low PS, Kularatne SA. Folate-targeted therapeutic and imaging agents for cancer. Curr Opin Chem Biol. 2009;13:256-62.

16. Song K, Kong B, Qu X, Li L, Yang Q. Phototoxicity of Hemoporfin to ovarian cancer. Biochem Biophys Res Commun. 2005;337(1):127-32.

17. Xiao K, Li YP, Joyce SL, Abby MG, Dong T, Gabriel F, et al. OA02 Peptide Facilitates the Precise Targeting of Paclitaxel-Loaded Micellar Nanoparticles to Ovarian Cancer In Vivo. Cancer Res. 2012;72:2100-10.

18. Zhao Y, Fu J, Ng Dennis KP, Wu C. Formation and degradation of poly (D,L-lactide) nanoparticles and their potential application as controllable releasing devices. Macromol Biosci. 2004;4:901-6.

19. Lee WC, Li YC, Chu IM. Amphiphilic poly (D,L-lactic acid)/poly(ethylene glycol)/poly (D,L-lactic acid) nanogels for controlled release of hydrophobic drugs. Macromol Biosci. 2006;6:846-54.

20. Kim K, Yu M, Zong X, Chiu J, Fang D, Seo YS, et al. Control of degradation rate and hydrophilicity in electrospun non-woven poly ( $D, L$-lactide) nanofiber scaffolds for biomedical applications. Biomaterials. 2003;24:4977-85.

21. Tang $X L$, Liang $Y$, Zhu YG, Xie CM, Yao AX, Chen L, et al. Anti-transferrin receptor-modified amphotericin B-loaded PLA-PEG nanoparticles cure Candidal meningitis and reduce drug toxicity. Int J Nanomedicine. 2015;10:6227-41.

22. Gref R, Minamitake Y, Peracchia MT, Trubetskoy V, Torchilin V, Langer R. Biodegradable long-circulating polymeric nanospheres. Science. 1994;263:1600-3.

23. Pan J, Zhao M, Liu Y, Wang B, Mi L, Yang L. Development of a new poly(ethylene glycol)-graft-poly(D,L-lactic acid) as potential drug carriers. J Biomed Mater Res A. 2009;89:160-7. 
24. Wang $B$, Jiang $W M$, Yan $H$, Zhang $X X$, Yang L, Deng LH, et al. Novel PEGgraft-PLA nanoparticles with the potential for encapsulation and controlled release of hydrophobic and hydrophilic medications in aqueous medium. Int J Nanomedicine. 2011;6:1443-51.

25. Alvarez-Berríos MP, Vivero-Escoto JL. In vitro evaluation of folic acidconjugated redox-responsive mesoporous silica nanoparticles for the delivery of cisplatin. Int J Nanomedicine. 2016;11:6251-65.

26. Wang X, Li J, Wang YX, Lydia K, Ada G, Paraskevi G. A Folate ReceptorTargeting Nanoparticle Minimizes Drug Resistance In A Human Cancer Model. ACS Nano. 2011;5:6184-94.

27. Ozols RF, Bundy BN, Greer BE, Fowler JM, Clarke-Pearson D, Burger RA, et al. Phase III trial of carboplatin and paclitaxel compared with cisplatin and paclitaxel in patients with optimally resected stage III ovarian cancer: a gynecologic oncology group study. J Clin Oncol. 2003;21:3194-200.

28. Webster L, Linsenmeyer M, Millward M, Morton C, Bishop J, Woodcock D. Measurement of cremophor EL following taxol: plasma levels sufficient to reverse drug exclusion mediated by the multidrug resistant phenotype. J Natl Cancer Inst. 1993;85:1685-95.

29. Fang J, Nakamura H, Maeda H. The EPR effect: unique features of tumor blood vessels for drug delivery, factors involved, and limitations and augmentation of the effect. Adv Drug Deliv Rev. 2011;63:136-51.

30. Mark JE, Mami M, Aniruddha R, Shyh DL. Factors controlling the pharmacokinetics, biodistribution and Intratumoral penetration of nanoparticles. J Control Release. 2013;172:782-94.

31. Zhang XY, Chen J, Zheng YF, Gao XL, Kang Y, Liu JC, et al. Folliclestimulating hormone peptide can facilitate paclitaxel nanoparticles to target ovarian carcinoma in vivo. Cancer Res. 2009;69:6506-14.

32. Shira J, WYY L, Scott AM. Biological Cleavage of the C-P Bond in Perfluoroalkyl Phosphinic Acids in Male Sprague-Dawley Rats and the Formation of Persistent and Reactive Metabolites. Environ Health Perspect. https://doi.org/10.1289/EHP1841.

33. Luis $N$, Larissa YR, Susanne KG, George RD, Bo L, Katrien R, et al. Decationized polyplexes as stable and safe carrier systems for improved biodistribution in systemic gene therapy. J Control Release. 2014;195:162-75.

34. Sun XL, Yan XF, Jacobson O, Sun WJ, Wang ZT, Tong X, et al. Improved tumor uptake by optimizing liposome based RES blockade strategy. Theranostics. 2017;7:319-28.

\section{Submit your next manuscript to BioMed Central and we will help you at every step:}

- We accept pre-submission inquiries

- Our selector tool helps you to find the most relevant journal

- We provide round the clock customer support

- Convenient online submission

- Thorough peer review

- Inclusion in PubMed and all major indexing services

- Maximum visibility for your research

Submit your manuscript at www.biomedcentral.com/submit

) Biomed Central 